\title{
Ionospheric signatures of the low-latitude boundary layer under conditions of northward IMF and small clock angle
}

\author{
S. E. Pryse ${ }^{1}$, R. W. Sims ${ }^{1, *}$, J. Moen ${ }^{2, * *}$, and K. Oksavik, ${ }^{2, * * *}$ \\ ${ }^{1}$ Institute of Mathematical and Physical Sciences, University of Wales, Aberystwyth, SY23 3BZ, UK \\ ${ }^{2}$ University of Oslo, Blindern, Norway \\ *now at: Medical Physics Directorate, University Hospital of North Staffordshire, Stoke-on-Trent, UK \\ ** also at: Arctic Geophysics, The University Centre in Svalbard, Longyearbyen, Norway \\ **** now at: JHU/APL, Laurel, Maryland, USA
}

Received: 29 July 2005 - Revised: 5 July 2006 - Accepted: 7 July 2006 - Published: 13 September 2006

\begin{abstract}
A case study is presented that concerns the footprints of the low-latitude boundary layer in the highlatitude ionosphere. The measurements were made near local magnetic noon in summertime under conditions of $B_{z}>0$ and small clock angle. Of particular interest are particle fluxes measured in the region by the NOAA-12 satellite that revealed energetic $(>30 \mathrm{keV})$ electrons, characteristic of trapped particles, together with a population of softer precipitating magnetosheath particles. The particle energydistribution was distinct from those identifying the central plasma sheet at lower latitudes. On its poleward side the layer extended to at least the latitude of the polar cap boundary as identified in ion flows and electron densities measured by the EISCAT Svalbard radar. It is proposed that the particles of the low-latitude boundary layer occurred on newlyclosed magnetic field lines, which were formed by the closure of open polar cap field by lobe reconnection in both Northern and Southern Hemispheres.
\end{abstract}

Keywords. Ionosphere (Ionosphere-magnetosphere interactions; Polar ionosphere) - Magnetospheric physics (Energetic particles, trapped)

\section{Introduction}

The influence of the solar wind on the Earth's ionosphere is highly dependent on the mechanisms that couple the two media. Magnetic reconnection between the interplanetary magnetic field (IMF) and the geomagnetic field (Dungey, 1961) is believed to play a key role. When the IMF has a southward component with a clock angle greater than $90^{\circ}$

Correspondence to: S. E. Pryse

(sep@aber.ac.uk) reconnection is likely at the magnetopause near the equatorial plane, while reconnection is more likely in the magnetospheric lobes, poleward of the cusp, under a northward IMF and small clock angle (Lockwood, 1998). Signatures of reconnection in the dayside high-latitude ionosphere have played a significant part in developing understanding of the coupling process and in identifying footprints of magnetospheric boundary layers.

The IMF clock angle is well-established as an ordering parameter for the characteristics of the high-latitude ionosphere, although many questions remain about the detail of its influence. It is known that a negative IMF $B_{z}$ component drives a two-cell high-latitude convection pattern with antisunward cross-polar flow and return sunward flows at lower latitudes in the dawn and dusk sectors (Reiff and Burch, 1985; Cowley, 1998). Satellite particle detectors have identified characteristic energies of incoming particles near the reconnection footprints (Newell and Meng, 1995) under the southward IMF condition, with evidence for velocity filter dispersion in the energy flux of precipitating ions (Rosenbauer et al., 1975). Spatial signatures in electron temperature have been identified by the EISCAT radars in regions that map to satellite ion energy dispersion (Pryse et al., 2000a), while radio tomography has identified reconnection footprints in the electron density (Walker et al., 1998). Locating the boundary between the closed terrestrial magnetic field and the open field lines connecting to the IMF is of current interest (Milan et al., 2003). Using measurements from the NOAA-12 satellite and auroral optics, Moen et al. (1996) identified the central plasma sheet (CPS) with magnetospheric electron flux, and the low-latitude boundary layer (LLBL) with magnetospheric ions embedded in a magnetosheath plasma. The boundary between the CPS and LLBL was associated with the most poleward closed

Published by Copernicus GmbH on behalf of the European Geosciences Union. 
field line. In a subsequent publication NOAA observations suggested the presence of trapped magnetospheric electrons within the magnetosheath-like plasma of the LLBL (Oksavik et al., 2000).

Ionospheric footprints under conditions of $B_{z}$ positive and lobe reconnection have not been so well studied. Under these conditions the high-latitude convection pattern comprises reverse convection cells with sunward plasma flow in the polar region and antisunward flow at lower polar latitudes, flanked by viscous cells on the dawn and duskside (Cowley, 1998). If the reverse cells are entirely on open magnetic field lines they are referred to as lobe cells (Reiff and Burch, 1985). DMSP particle data have revealed reverse ion energy dispersion characteristic of the reconnection with energy decreasing with decreasing latitude (Øieroset et al., 1997), radio tomography has identified spatial structures in the electron density distribution (Pryse et al., 2000b) and recently Oksavik et al. (2006) have documented that electron density structures may form inside lobe cells due to soft electron precipitation. In its simplest form, an adiaroic boundary separates the polar regime on open magnetic field lines from the lower-latitude viscous regime on closed field lines, across which plasma cannot enter or leave the polar cap. The boundary between the two regimes has been identified at small IMF clock angles in ion flow measurements by the EISCAT Svalbard radar (ESR) by comparison with the equatorward boundary of redline cusp emission (Pryse et al., 2000b), and it was also a feature of the ESR flow observations of Pitout et al. (2001) under $B_{z}$ positive but with variable clock angle. Milan et al. (2003) used low level UV aurora in the polar cap, co-located with magnetosheath precipitation, to locate the open/closed magnetic field line boundary under northward IMF, identifying the boundary with the equatorward edge of the emission.

Studies of magnetic reconnection under northward IMF using in-situ spacecraft measurements are of considerable interest, in particular in relation to the origin of the plasma in the LLBL. The existence of magnetosheath plasma in the inner LLBL on the earthward side of the magnetopause is a subject of debate, with the mechanism by which it crosses the magnetopause being an open question (Phan et al., 2005; Lavraud et al., 2005 and references within). Some studies favour diffusive entry, whilst others cite the KelvinHelmholtz instability as the process. An alternative mechanism is based on the prediction of Song and Russell (1992), which proposes that newly closed magnetospheric field lines are formed at the dayside magnetopause when the IMF is strongly positive by reconnection in both northern and southern lobes. This double reconnection was subsequently supported by case studies using in-situ spacecraft measurements (Le et al., 1996; Onsager et al., 2001). Theoretical aspects of the internal reconnection also remain of interest, with different topologies for reconnection being suggested. Watanabe et al. (2005) indicate, for example, the possibility of reconnection in the high-latitude, summer hemisphere magnetopause between a northward IMF and a closed geomagnetic field line, followed by closure of the opened field by reconnection in the winter hemisphere. To date most observations to substantiate the theories have been from in-situ spacecraft observations. However, such measurements are somewhat limited with a spacecraft only being able to sample one region of space at any given time. In principle, low-altitude observations in the ionised atmosphere should be able to reveal signatures of this double reconnection when mapped down the converging geomagnetic field lines, and increase the experimental evidence for the proposed mechanisms. Resulting merging convection cells are anticipated to have open lobe flux tubes in the sunward flow at their centre, which are subsequently closed at lower latitudes by reconnection in the other hemisphere (Crooker, 1992). Such reconnection in both hemispheres was proposed by Lockwood and Moen (1999) as an explanation for their observations of optical emissions, while Sandholt et al. (1999) present optical and satellite data indicating the capture of magnetosheath plasma by the magnetosphere under the condition. However, there has not been much coverage of the ionospheric signature of double reconnection in the literature.

A case study is presented in this current paper where lowaltitude observations suggest that reconnection was occurring simultaneously in the two hemispheres under conditions of IMF northward and small clock angle. The background ionospheric conditions were monitored by the EISCAT Svalbard radar running in a special programme mode near magnetic noon on 24 August 2000, and observations of the incoming particle flux distributions were made almost coincidentally by the NOAA-12 satellite.

\section{Experimental observations}

\subsection{Interplanetary magnetic field}

The orientation and magnitude of the interplanetary magnetic field impinging on the Earth's magnetosphere at the time of interest was established from measurements by the ACE spacecraft. The spacecraft, positioned upstream of the Earth in the solar wind at $(243.5,-18.2,33.0) R_{E}$, measured a relatively constant solar wind speed of about $310 \mathrm{~km} \mathrm{~s}^{-1}$, giving an estimated delay of $95 \mathrm{~min}$ for the ionospheric response (Lockwood et al., 1989). The three components of the interplanetary magnetic field (IMF) observed between 05:00 UT and 08:00 UT are shown in the first three panels of Fig. 1. The bottom panel shows the corresponding clock angle defined as:

$$
\begin{aligned}
& \theta=\tan ^{-1}\left(\left|B_{y} / B_{z}\right|\right) \text { for } B_{z}>0 \\
& \theta=180^{\circ}-\tan ^{-1}\left(\left|B_{y} / B_{z}\right|\right) \text { for } B_{z}<0,
\end{aligned}
$$

where $B_{y}$ and $B_{z}$ are the conventionally defined components of the IMF. Values of $0^{\circ}<\theta<90^{\circ}$ are indicative of positive (northward) $B_{z}$ and $90^{\circ}<\theta<180^{\circ}$ of negative (southward) $B_{z}$. 

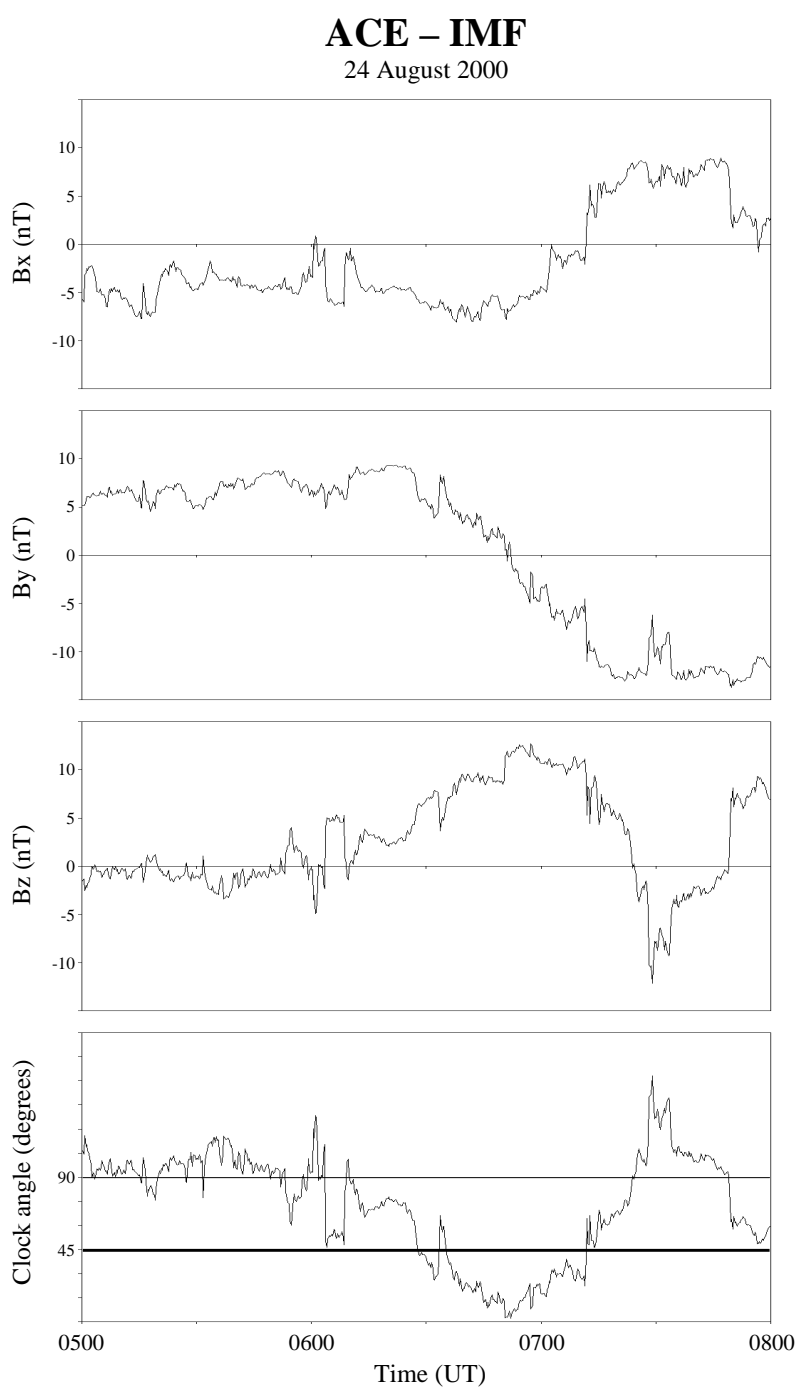

Fig. 1. The three components of the IMF (top three panels) measured by the ACE satellite on 24 August 2000 between 05:00 UT and 08:00 UT and the corresponding clock angle (bottom panel).

Of particular interest to the study is the time period between about 06:30 UT and 07:10 UT when the IMF was predominantly northward with a clock angle less than $45^{\circ}$. This configuration was likely to be supporting reconnection in the magnetospheric lobes, with the negative $B_{x}$ favouring reconnection in the Northern Hemisphere (Crooker and Rich, 1993). Given the anticipated delay, the signature of the reconnection is expected to be observed in the ionosphere between about 08:05 UT and 08:45 UT.

\subsection{Background ionospheric plasma}

Background ionospheric plasma conditions during the interval of interest were established using the EISCAT (European Incoherent Scatter) radar facility at Longyearbyen, Svalbard. The EISCAT Svalbard Radar (ESR) at $78.2^{\circ} \mathrm{N}$,

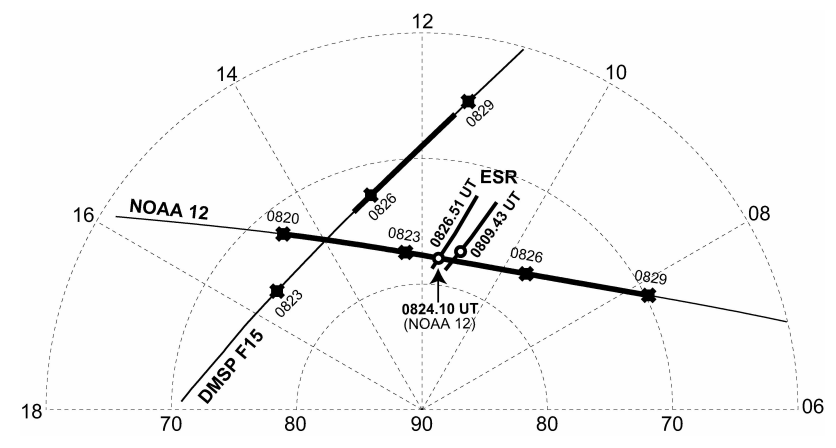

Fig. 2. Geometry plot in the geomagnetic reference frame (MLAT versus MLT) showing the 300-km intersection of the two ESR radar scans near 11 MLT and trajectory projections of the NOAA-12 and DMSP F15 satellite passes. The black circles on the ESR traces show the locations of the boundaries in the line-of-sight ion drift and electron density at 08:09.43 UT and 08:26.51 UT respectively. The bold part of the DMSP F15 path between 08:25.24 UT and 08:28.37 UT shows the region of CPS particle fluxes, whilst the bold part on the NOAA-12 path between 08:20.02 UT and 08:29.02 UT shows the region identified as LLBL. The times on the NOAA track refer to UT epochs and are chosen to match time markers on the observed fluxes in Fig. 4.

$16.1^{\circ} \mathrm{E}\left(75.0^{\circ} \mathrm{MLAT}, 113.1^{\circ} \mathrm{MLON}\right)$ was operating in the UK NOON special programme mode, observing in repeated north-to-south latitudinal scans of 20-min duration from about $81^{\circ} \mathrm{N}$ to $75^{\circ} \mathrm{N}$ at an altitude of $300 \mathrm{~km}$, with latitudinal steps of $0.18^{\circ}(\sim 20 \mathrm{~km})$ every $32 \mathrm{~s}$. The data presented have been postintegrated over $64 \mathrm{~s}$, two pointing directions, for improved signal-to-noise ratio. Figure 2 shows the geometry of the $300-\mathrm{km}$ intersection of the ESR radar beam for two scans at the time of interest in the geomagnetic reference frame. The scans near 11:00 MLT extend between about $72^{\circ} \mathrm{MLAT}$ and $78^{\circ} \mathrm{MLAT}$.

\subsubsection{Line-of-sight ion drift}

The component of ion drift along the ESR radar beam for the two scans that started at 08:04 UT and 08:24 UT respectively are shown in the top two panels of Fig. 3. Two clear regimes are evident in both panels: a northernmost region with flow components attaining in excess of $500 \mathrm{~m} \mathrm{~s}^{-1}$ toward the radar, separated by a clear boundary near $80^{\circ} \mathrm{N}$ from a lower-latitude region with small velocity components. The fast flow was accompanied by increased ion temperatures associated with ion-neutral frictional heating. The boundaries between the two regimes indicated in black on the panels are set where the velocity components are essentially zero. The location is a few degrees latitude north of the radar location, ruling out geometrical effects as causing an apparent boundary at the radar zenith where the beam is insensitive to horizontal flow. Closer examination reveals that the boundary occurs near $79.5^{\circ} \mathrm{N}$ in the first scan, whereas by the observation of the second scan it has moved poleward. The 

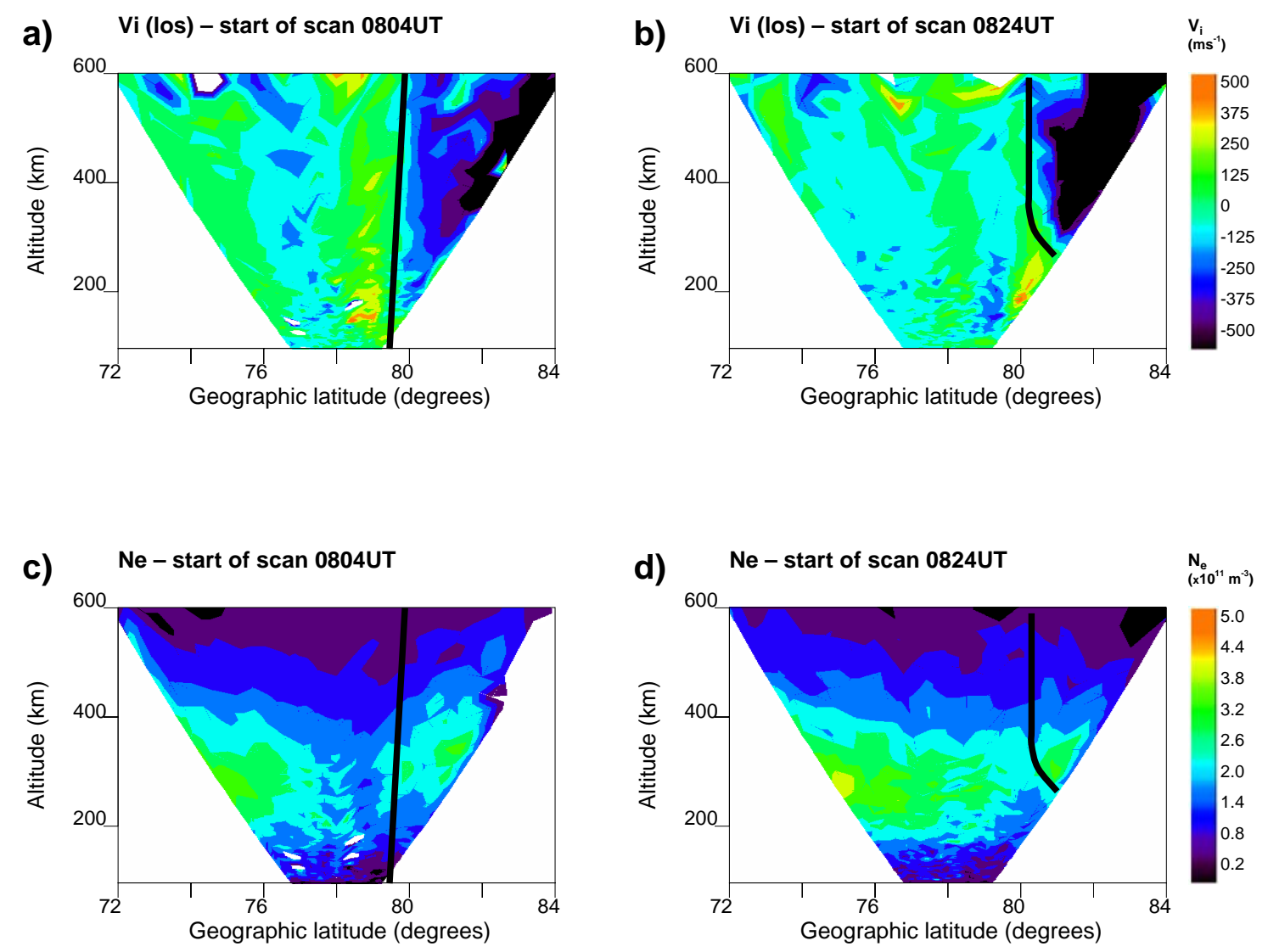

Fig. 3. The line-of-sight ion drift component measured by the ESR along the radar beam during scans staring from the north at (a) 08:04 UT and (b) 08:24 UT on 24 August 2000. The location of the boundaries that were observed at 08:09.43 UT and 08:26.51 UT, respectively in the ion drift are shown in black near $80^{\circ} \mathrm{N}$. Panels (c) and (d) show the corresponding electron densities.

boundary in the later scan, which will be of main interest for later discussion, is at $80.3^{\circ} \pm 0.2^{\circ} \mathrm{N}$ near the F-region peak, with the uncertainty being commensurate with the latitudinal step of the radar beam at $300 \mathrm{~km}$. The location of the boundary at $79.5^{\circ} \mathrm{N}$ in the first scan at 08:09.43 UT and its poleward extreme at $80.5^{\circ} \mathrm{N}$ in the second scan at 08:26.51 UT are indicated in magnetic terms on the geometry plot (Fig. 2) by the black circles on the two ESR traces.

An abrupt boundary in ion flows measured by the ESR radar was presented in Pryse et al. (2000b). Comparisons of the boundary location with optical emissions and plasma drift measured by the CUTLASS radar, showed it to be located at the equatorward edge of the polar cap where the sunward flow of the reverse polar cells, in this instance lobe cells, gave way to the viscous cells at lower latitudes. In the observations of the current paper, it is not possible to obtain the full vector velocity of the flow due to the ESR measuring the component of flow directed towards the radar. However, such a sharp transition as shown in Fig. 3 from fast equatorward velocity components in excess of $500 \mathrm{~m} \mathrm{~s}^{-1}$ to small poleward velocity components is likely to occur in the re- gion where the sunward flow of reverse cells gives way at the edge of the polar cap to the weak meridional flows at lower latitudes.

\subsubsection{Electron density distribution}

The two regimes on either side of the boundary in ion drift are also revealed in the spatial electron density distributions measured by the ESR (bottom two panels of Fig. 3). Poleward of the boundary is plasma in the polar cap, whilst photoionisation occurs on the equatorward side with the lower latitude plasma extending to higher latitudes by the second scan. This extension of the photoionisation is mainly in response to a decreasing solar zenith angle, but it is possible that poleward convection in the weak viscous cells also contributes in the scan starting 08:24 UT.

The coincident abrupt transition in both the line-of-sight ion drift and the electron density clearly signify a boundary between two regimes. Taken collectively these are used as a proxy of the boundary of the polar cap. Whilst the open/closed boundary of the geomagnetic field cannot be categorically identified, it is likely to be near this transition in 
flow and electron density. To the north is the polar cap where the field lines are open and on the southern side a weak viscous regime on closed field lines.

\subsection{Particle flux}

2.3.1 National Oceanographic and Atmospheric Administration (NOAA) satellite

Of particular interest to the current paper are measurements of fluxes of precipitating and trapped particles made by NOAA-12, a satellite in circular orbit at an altitude of about $815 \mathrm{~km}$ that crosses the northern cusp/cleft region from dusk to dawn. The satellite is part of the National Oceanic and Atmospheric Administration and Television and Infrared Observation Satellite program, and further details of the satellites and their sensors are given by Raben et al. (1995).

NOAA-12 passed near Svalbard during the time of interest, reaching its highest invariant latitude of $77.5^{\circ}$ ILAT at 08:24.25 UT and 11:22 MLT. Its trajectory mapped to an altitude of $300 \mathrm{~km}$ is indicated in geomagnetic terms in Fig. 2, where the magnetic latitudes are in MLAT. The path essentially intersected the poleward extreme of the boundary identified in the ESR ion flows almost concurrent in time with the radar observation, with the satellite observing the region near 08:24.10 UT less than three minutes before the ESR observed the same region at 08:26.51 UT.

The five panels of Fig. 4 show the measured integrated flux for electrons with energies (a) $300-458 \mathrm{eV}$, (b) $>30 \mathrm{keV}$, (c) $>100 \mathrm{keV}$ and ions with energies (d) $0.3-2.5 \mathrm{keV}$, (e) $30-$ $80 \mathrm{keV}$. In panels (b) and (c) the dashed and solid curves are for trapped and precipitating particles respectively with pitch angles near $80^{\circ}$ and $10^{\circ}$, respectively. Panel (e) shows the flux of the precipitating ions in the $30-80 \mathrm{keV}$ channel; information was not available for the trapped ions. The vertical dashed line through the panels indicates the location of the intersection of the satellite trajectory with the ESR scan plane near the upper uncertainty limit of the polar cap boundary identified by the radar, whilst the two solid lines on either side of the intersection indicate the locations of the magnetic latitude of the lower uncertainty limit of the boundary. The locations of the lower limits of the boundary in the figure are displaced in longitude from that of the scan, and their geographic latitudes are therefore different to that of the boundary limit on the ESR scan. The polar cap boundary identified by the ESR is thus anticipated to be at a magnetic latitude poleward of the solid lines but equatorward of the dashed line.

Of particular interest is the part of panel (b) that reveals the presence of significant fluxes of high energy electrons (>30 keV) between 08:20.02 UT and 08:29.02 UT, but with flux levels that are significantly lower than in the traditionally classified central plasma sheet regions on closed field lines observed prior to 08:20.02 UT and between 08:29.02 UT and 08:32.20 UT. The fluxes of trapped electrons in this re- gion between 08:20.02 UT and 08:29.02 UT are generally higher than those of precipitating particles, except within the two solid lines where the fluxes of both are essentially equal suggesting that the pitch angle distribution is isotropic. The region of reduced, albeit significant electron fluxes, at latitudes poleward of the CPS is identified as the ionospheric signature of the LLBL under northward IMF and has a particle flux distribution akin to that reported by Oksavik et al. (2000) for NOAA observations under conditions of negative IMF $B_{z}$. Its location is indicated by the bold black part of the NOAA 12 trajectory in Fig. 2. The region of interest also has a population of magnetosheath-type ions (0.3$2.5 \mathrm{keV}$ ) which is revealed in panel (d) and low energy (300$458 \mathrm{eV}$ ) electrons shown in panel (a), characteristic of open magnetosheath field lines. Clear gradients in flux separate the regimes of the large fluxes of high-energy electron in the CPS and the reduced fluxes at the poleward most extreme of the satellite trajectory (panel (b)) although they are not very steep, a likely consequence of the east-west satellite trajectory intersecting the CPS/LLBL boundary obliquely. The transits of the satellite through the CPS/LLBL boundary are identified in this study to be at 08:20.02 UT (71.6 ILAT, 14:34 MLT) and 08:29.02 UT (70.6 ILAT, 07:55 MLT) coincident with the sharp boundaries on either side of the measured fluxes of magnetosheath-type ions $(0.3-2.5 \mathrm{keV})$ in panel (d), and are indicated by the vertical dotted lines in the figure. The low energy electrons $(300-458 \mathrm{eV}$ ) in panel (a) and the $30-80 \mathrm{keV}$ ions shown in panel (e) also show a tendency for higher fluxes between these two markers for the CPS/LLBL boundary, but with levels tapering to lower latitudes rather than decreasing abruptly.

\subsubsection{Defense meteorological satellite programme (DMSP)}

The DMSP F15 satellite traversed the noon-time ionosphere at the time of interest, although it was displaced in MLT from the ESR observations. An abrupt boundary in the electron flux at 08:25.24 UT (72.9 $9^{\circ}$ MLAT, 13:11 MLT) during the pass (not shown) identified the poleward edge of the CPS, which then gave way at higher latitudes to the traditional boundary plasma sheet (BPS) at the higher latitudes in the afternoon sector. The trajectory of the DMSP F15 satellite is shown in Fig. 2 with the CPS region indicated in bold. The trajectory of the satellite did not reach sufficiently high latitudes in the noon sector to intersect the latitudes of main interest near the polar cap boundary, nevertheless it indicated that the poleward edge of the CPS was several degrees equatorward of the boundary. Comparison of the NOAA and DMSP fluxes in the afternoon sector suggests ambiguity in the classification of particles, with NOAA indicating LLBL but DMSP revealing BPS. The cause for this is attributed to the combined LLBL/BPS interpretation used for the NOAA observations as in Oksavik et al. (2000). However, in the region of particular interest for the current study at the polar cap boundary near magnetic noon the footprint is likely to be 

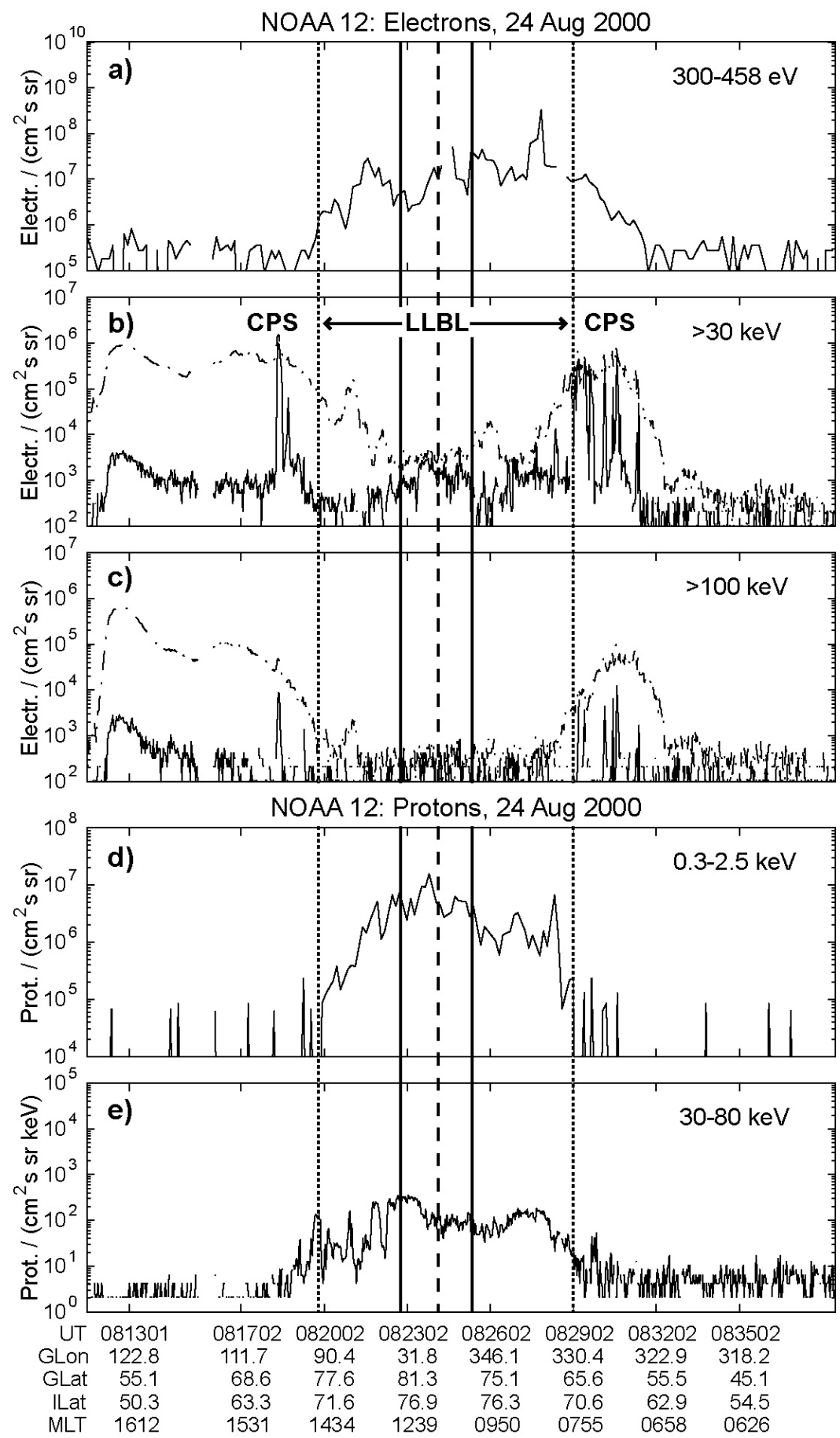

Fig. 4. Integrated fluxes measured by the NOAA-12 satellite between 08:13 UT and 08:35 UT on 24 August 2000 for electrons with energies (a) 300-458 eV, (b) $>30 \mathrm{keV}$, (c) $>100 \mathrm{keV}$ and ions with energies (d) $0.3-2.5 \mathrm{keV}$, (e) 30-80 keV. In panels (b) and (c) the dashed and solid curves are for trapped and precipitating particles with pitch angles near $80^{\circ}$ and $10^{\circ}$ respectively. The vertical dashed line indicates the location of the intersection of the satellite trajectory with the ESR scan plane. This line also coincides with the poleward extreme of the polar cap boundary identified by the radar when the uncertainty is taken into consideration. The two solid lines on either side indicate the magnetic latitude of the equatorward uncertainty limit of the boundary seen by ESR, although these are displaced in longitude from the plane of the ESR scan. The two dotted lines indicate the poleward boundary of the CPS as defined in the text and the LLBL covers the region between these two dotted lines. 
that of the LLBL, and the issue of separating the LLBL and BPS is not pursued further here.

\section{Discussion}

Observations have been presented of low-altitude signatures of magnetospheric boundary layers under conditions of IMF $B_{z}$ positive. Particle fluxes were identified by the NOAA12 and DMSP F15 satellites, and measurements of the background ionospheric plasma parameters provided by the ESR radar. Of particular interest to the study was a region near magnetic noon where NOAA flux measurements indicated the presence of both magnetospheric high-energy electrons and low-energy magnetosheath particles. The former are indicative of trapped electrons, usually on closed magnetic field lines, whilst the latter are characteristic of open polar field lines. This region identified as the LLBL by the NOAA observations was clearly distinct from the CPS region at lower latitudes, where the fluxes of the higher energy electrons were significantly higher and those of the soft particles essentially absent. The latitudinal coverage of the ionospheric LLBL extended from its boundary with the CPS at about $73.0^{\circ}$ MLAT to at least $77.3^{\circ}$ MLAT near the polar cap boundary. We cannot be precise about its poleward extreme as it may have extended beyond the most northerly magnetic latitude of the satellite trajectory. The schematic in Fig. 5 with 12MLT on top and dawn on the right-hand-side indicates the interpretation of the observations, illustrating the CPS regime, CPS/LLBL boundary and the LLBL regime together with the equipotential contours of a part of the dawn reverse cell. Also indicated are the ESR scan intersections, the earlier scan labeled 1 and the later scan labeled 2. The polar cap boundary at the time of the earlier scan occurs at the intersection of the ESR trace 1 with the equatorward edge of the reverse cell shown by the dashed curve. By the time of observation of the boundary in the second ESR scan it has receded poleward to the intersection of ESR trace 2 with the adjacent solid black equipotential. Meanwhile it is likely that field lines have been closing between the two boundary locations.

Most studies of the ionospheric signatures of open/closed magnetic field line boundaries have been carried out for conditions of $B_{z}$ negative in wintertime when observations of optical emissions are available. Under conditions of southward IMF closed field lines are opened by reconnection near the equatorial magnetopause. One of the most accepted proxies for the open/closed boundary on the dayside is the poleward edge of high energy trapped electrons. At latitudes poleward of this boundary the particle energies are characteristic of magnetosheath particles indicative of field lines directly open to the magnetosheath and solar wind. Moen et al. (1998) used this traditional definition and identified the open/closed boundary at the poleward edge of trapped $>30 \mathrm{keV}$ electrons in the CPS. However, in a subsequent in-
12 MLT

CPS

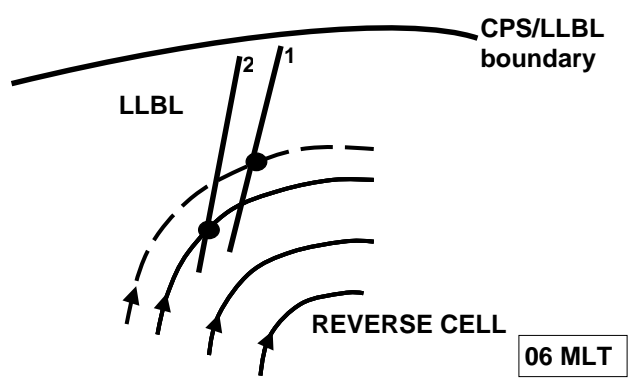

Fig. 5. A schematic illustration of identified regions with magnetic noon at the top of the diagram and dawn on the right-hand side. It shows the CPS, CPS/LLBL boundary and the LLBL, the location of ESR observations and a portion of the equipotential contours of the dawn reverse cell. The polar cap boundary lies on the intersection of the ESR trace 1 and the dashed equipotential curve at the time of the first radar scan. By the time of the second scan the polar cap boundary has receded poleward to the intersection of ESR trace 2 and the adjacent solid curve.

vestigation, also under conditions of IMF $B_{z}<0$, Oksavik et al. (2000) realised by plotting fluxes on logarithmic scale, that the fluxes of energetic electrons poleward of the CPS did not drop to the background noise level, although the levels were significantly less than in the CPS. This region, with a mixture of low fluxes of electrons with energies $>30 \mathrm{keV}$ characteristic of trapped particles and magnetosheath particles, was identified as the footprint of the LLBL. The study highlighted that identification of the open/closed boundary is not straight forward even from satellite particle data, in particular as in this instance DMSP satellite measurements indicated that the LLBL region was on open field lines.

Unlike many previous studies, the current investigation occurs under conditions of $B_{z}$ positive and summertime when optical measurements are not available. It is believed that reconnection occurs in the magnetospheric lobes when the IMF $B_{z}$ is positive and the clock angle is sufficiently small. Freeman et al. (1993) found that the sunward cross-polar flow of the lobe reconnection persisted up to a clock angle of about $70^{\circ}$, before it gave way to the antisunward convection characteristic of low-latitude reconnection. In the current study the clock angle at the time of interest was less than $45^{\circ}$ with $B_{x}<0$ favouring the reconnection to occur in the northern magnetospheric lobe. The observation of high energy magnetospheric electrons equatorward of the polar cap boundary is not unexpected, with the field lines anticipated to be closed in the region under conditions of lobe reconnection. However, it appears that there are two regimes of high-energy particles. The first, at the lower latitudes, is the region of the traditional closed field lines associated with the CPS identified by both the NOAA and DMSP satellites. The second is a 
region poleward of the CPS, identified as the footprint of the LLBL. Within this region there is a low but significant flux of energetic ( $>30 \mathrm{keV}$ ) electrons and also fluxes of low energy magnetosheath plasma, a distribution similar to that identified by the NOAA observations in the LLBL under southward IMF (Oksavik et al., 2000). It may be that this region of LLBL signature on closed field lines poleward of the CPS corresponds to that of the inner region of a multi-layer LLBL structure observed in situ in the study of Song et al. (1990). However, in the present case the NOAA satellite trajectory did not extend to sufficiently high latitudes for the layer to be clearly distinguished from an outer layer mapping to the reverse convection cell, should it have existed, although it can be noted that at the poleward extreme of the pass in the vicinity of the polar cap boundary the small fluxes of precipitating and trapped high-energy electrons become essentially equal. There may also be correspondence between the LLBL region reported in the current study and the Boundary Plasma Region (BPR) reported by Rich et al. (1990), although the satellite observations in the earlier paper were made during a geomagnetic storm with the IMF being northward for a period of hours. Moreover, the electron and ion populations in the BPR had magnetosheath characteristics. Consolidation of different results will require further observations, both in situ and at low-altitude, under a range of different geomagnetic conditions.

Regions of mixed magnetospheric electrons and magnetosheath particles are not well understood. It was proposed by Lockwood (1998) that the mixing layer under IMF $B_{z}<0$ is on open field lines between the central plasma sheet and the flow-reversal boundary. Moen et al. (2004) observed such a layer and associated it with a low-latitude boundary mixing layer on open field lines. Explanations put forward include the penetration of ring current electrons from the CPS into the LLBL by gradient-B and curvature-B drifts (Moen et al., 2004; Lockwood, 1998), and maintenance of magnetospheric particle fluxes by magnetic bottles on open field lines (Cowley and Lewis, 1990). This current paper presents observations of such a mixing layer under conditions of lobe reconnection, with $B_{z}>0$ and small clock angle. Under these conditions it is even more difficult to explain the occurrence of high energy electrons within the LLBL region, with the high energy magnetospheric electrons occurring at latitudes some 4 to 5 degrees poleward of the traditional closed CPS. As an explanation of the observations we suggest that the particles within the LLBL were on field lines that were originally opened under earlier conditions of equatorial reconnection, but were then closed by lobe reconnection in both Northern and Southern Hemispheres when the clock angle was sufficiently small. Reconnection in the northern lobe between these open field lines and the IMF would give rise to overdraped field lines with one end in the Northern Hemisphere, and subsequent reconnection of the field lines in the southern lobe would then create closed field lines. Such double reconnection was proposed by Song and Russell (1992), and supported by spacecraft observations (Le et al., 1996; Onsager et al., 2001) and by ionospheric optical measurements (Lockwood and Moen, 1999; Sandholt et al., 1999). The footprint of the newly-closed field lines are likely to occur at increasing latitude as the polar cap boundary moves poleward, illustrated schematically in Fig. 5 by the displacement between the dashed equipotential curve and adjacent solid equipotential curve of the reverse, merging cell in the time interval between the two ESR scans. The means of populating the newly-closed field lines with magnetospheric high-energy electrons remains an open question, with the polar field lines from which the closed field is created unlikely to support magnetospheric electrons before closure. Mechanisms already invoked under $B_{z}<0$ may be responsible, with, for example, ring current electrons penetrating poleward, although this would require penetration over several degrees latitude. The double reconnection mechanism would also explain the population of magnetosheath ions in the LLBL, with the particle distribution of the polar open field-lines being captured on newly-closed field lines.

It is appreciated that the observations presented were made during a single case event in summertime when optical observations are not available, and that more general findings are desirable. However, additional data for similar studies are not currently available to us. This is not surprising given that the measurements were made during special programme observations by the ESR radar during limited time intervals, and the requirement of coincident satellite observations. Nevertheless we believe that this single summertime case study is of interest, in particular because of the current interest in LLBL plasma characteristics under northward IMF conditions.

\section{Conclusions}

Particle flux observations by the NOAA-12 and DMSP F15 satellites and background conditions identified by the ESR radar and the ACE spacecraft have been used to identify lowaltitude signatures of the LLBL magnetospheric layer under conditions of positive IMF $B_{z}$ in summertime. The ionospheric signature of the region extended over several degrees latitude from the poleward edge of the footprint of the CPS to at least the latitude of the polar cap boundary as identified by the ion flows of the reverse convection cell near magnetic noon. The NOAA particle fluxes revealed a mixture of magnetosheath particles and high-energy magnetospheric electrons in the region, with the intensity of the high-energy electrons being significantly lower than in the CPS. The LLBL layer was interpreted as being on newly closed magnetic field lines, formed by the closure of open polar cap field by reconnection with the IMF in both the Northern and Southern Hemispheres. 
Acknowledgements. Financial support for the project was provided by the UK Particle Physics and Astronomy Research Council under grant PPA/G/O/2003/00017 and by the Norwegian Research Council and AFOSR task 2311AS. EISCAT is an international facility supported by the national science councils of Finland, France, Germany, Japan, Norway, Sweden and the United Kingdom. K. Oksavik would like to thank D. S. Evans at the NOAA Space Environment Center for providing NOAA-12 particle data. The DMSP particle boundary was obtained via the JHU/APL website, and the IMF data was obtained through the CDAWeb. R. W. Sims acknowledges receipt of a PPARC postgraduate studentship.

Topical Editor M. Pinnock thanks G. Chisham and another referee for their help in evaluating this paper.

\section{References}

Crooker, N. U.: Reverse Convection, J. Geophys. Res., 97 (A12), 19363-19372, 1992.

Crooker, N. U. and Rich, F. J.: Lobe-cell convection as a summer phenomenon, J. Geophys. Res., 98 (A8), 13 403-13 407, 1993.

Cowley, S. W. H.: Excitation of flow in the Earth's magnetosphereionosphere system: observations by incoherent scatter radar, in: Polar Cap Boundary Phenomena, edited by: Moen, J., Egeland, A., and Lockwood, M., NATO Advanced Study Institute Series, Kluwer Academic Press, Dordrecht, The Netherlands, 509, 127140, 1998.

Cowley, S. W. H. and Lewis, Z. V.: Magnetic trapping of energetic particles on open dayside boundary layer flux tubes, Planet. Space Sci., 38 (10), 1343-1350, 1990.

Dungey, J. W.: Interplanetary magnetic field and auroral zones, Phys. Rev. Lett., 6 (2), 47-48, 1961.

Freeman, M. P., Farrugia, C. J., Burlaga, L. F., Hairston, M. R., Greenspan, M. E., Ruohoniemi, J. M., and Lepping, R. P.: The interaction of a magnetic cloud with the Earth: ionospheric convection in the Northern and Southern Hemispheres for a wide range of quasi-steady interplanetary magnetic field conditions, J. Geophys. Res., 98 (A5), 7633-7655, 1993.

Lavraud, B., Thomsen, M. F., Taylor, M. G. G. T., Wang, Y. L., Phan, T. D., Schwartz, S. J., Elphic, R. C., Fazakerley, A., Rème, H., and Balogh, A.: Characteristics of the magnetosheath electron boundary layer under northward interplanetary magnetic field: Implications for high-latitude reconnection, J. Geophys. Res., 110, A06209, doi:10.1029/2004JA010808, 2005.

Le, G., Russell, C. T., Gosling, J. T., and Thomsen, M. F.: ISEE observations of low-latitude boundary layer for northward interplanetary magnetic field: Implications for cusp reconnection, J. Geophys. Res., 101 (A12), 27 23-2 249, 1996.

Lockwood, M.: Identifying the open-closed field line boundary, in Polar Cap Boundary Phenomena, edited by: Moen, J., Egeland, A., and Lockwood, M., NATO Advanced Study Institute Series, Kluwer Academic Press, Dordrecht, The Netherlands, 509, 7390, 1998.

Lockwood, M. and Moen, J.: Reconfiguration and closure of lobe flux by reconnection during northward IMF: possible evidence for signatures in cusp/cleft auroral emissions, Ann. Geophys., 17, 996-1011, 1999, http://www.ann-geophys.net/17/996/1999/.

Lockwood, M., Sandholt, P. E., Cowley, S. W. H., and Oguti, T.: Interplanetary magnetic field control of dayside auroral activity and the transfer of momentum across the dayside magnetopause, Planet. Space Sci., 37 (11), 1347-1365, 1989.

Milan, S. E., Lester, M., Cowley, S. W. H., Oksavik, K., Brittnacher, M., Greenwald, R. A., Sofko, G., and Villain, J. P.: Variations in the polar cap area during two substorm cycles, Ann. Geophys., 21, 1121-1140, 2003, http://www.ann-geophys.net/21/1121/2003/.

Moen, J., Lockwood, M., Oksavik, K., Carlson, H. C., Denig, W. F., van Eyken, A. P., and McCrea, I. W.: The dynamics and relationships of precipitation, temperature and convection boundaries in the dayside auroral ionosphere, Ann. Geophys., 22, 1973-1987, 2004, http://www.ann-geophys.net/22/1973/2004/.

Moen, J., Evans, D., and Carlson, H. C.: NOAA-12 satellite and ground correlative study of cusp/cleft aurora above Svalbard, Adv. Space Res., 22 (9), 1319-1322, 1998.

Moen, J., Evans, D., Carlson, H. C., and Lockwood, M.: Dayside moving auroral transients related to LLBL dynamics, Geophys. Res. Lett., 23 (22), 3247-3250, 1996.

Newell, P. T. and Meng, C.-I.: Cusp low-energy ion cutoffs: a survey and implications for merging, J. Geophys. Res., 100 (A11), 21 943-21 951, 1995.

Oksavik, K., Ruohoniemi, J. M., Greenwald, R. A., Baker, J. B. H., Moen, J., Carlson, H. C., Yeoman, T. K., and Lester, M.: Observations of isolated polar cap patches by the EISCAT Svalbard and SuperDARN Finland radars, J. Geophys. Res., doi:10.1029/2005JA011400, 2006.

Oksavik, K., Soraas, F., Moen, J., and Burke, W. J.: Optical and particle signatures of magnetospheric boundary layers near magnetic noon: satellite and ground-based observations, J. Geophys. Res., 105 (A12), 27 555-27 568, 2000.

Onsager, T. D., Scudder, J. D., Lockwood, M., and Russell, C. T.: Reconnection at the high-latitude magnetopause during northward interplanetary magnetic field conditions, J. Geophys Res., 106 (A11), 25 467-25 488, 2001.

Phan, T. D., Oieroset, M., and Fujimoto, M.: Reconnection at the dayside low-latitude magnetopause and its nonrole in low-latitude boundary layer formation during northward interplanetary magnetic field, Geophys. Res. Lett., 32, L17101, doi:10.1029/2005GL023355, 2005.

Pitout, F., Bosqued, J. M., Alcayde, D., Denig, W. R., and Rème, H.: Observations of the cusp region under northward IMF, Ann. Geophys., 19, 1641-1653, 2001, http://www.ann-geophys.net/19/1641/2001/.

Pryse, S. E., Smith, A. M., Walker, I. K., and Kersley, L.: Multiinstrument study of footprints of magnetopause reconnection in the summer ionosphere, Ann. Geophys., 18, 1118-1127, 2000a.

Pryse, S. E., Smith, A. M., Kersley, L., Walker, I. K., Mitchell, C. N., Moen, J., and Smith, R. W.: Multi-instrument probing of the polar ionosphere under steady northward IMF, Ann. Geophys., 18, 90-98, 2000b.

Raben, V. J., Evans, D. S., Sauer, H. H., Sahm, S. R., and Huynh, M.: TIROS/NOAA satellite space environment monitor data archive documentation: 1995 update, Technical report, Space Environment Laboratory, Boulder, Colorado, 1995.

Reiff, P. H. and Burch, J. L.: IMF By-dependent plasma flow and Birkeland currents in the dayside magnetosphere: 2. A global model for northward and southward IMF, J. Geophys. Res., 90 (NA2), 1595-1609, 1985. 
Rich, F. J., Hardy, D. A., Redus, R. H., and Gussenhoven, M. S.: Northward IMF and patterns of high-latitude precipitation and field-aligned currents - the February 1986 storm, J. Geophys. Res., 95 (A6), 7893-7913, 1990.

Rosenbauer, H., Grunwaldt, H., Montgomery, M. D., Paschmann, G., and Sckopke, N.: HEOS-2 plasma observations in the distant polar magnetosphere: plasma mantle, J. Geophys. Res., 80 (19), 2723-2737, 1975.

Sandholt, P. E., Farrugia, C. J., Cowley, S. W. H., Denig, W. F., Lester, M., Moen, J., and Lybekk, B.: Capture of magnetosheath plasma by the magnetosphere during northward IMF, Geophys. Res. Lett., 26 (18), 2833-2836, 1999.

Song, P. and Russell, C. T.: Model of the formation of the low latitude boundary layer for strongly northward interplanetary magnetic field, J. Geophys. Res., 97 (A2), 1411-1420, 1992.

Song, P., Elphic, R. C., Russell, C. T., Gosling, J. T., and Cattell, C. A.: Structure and properties of the subsolar magnetopause for northward IMF - ISEE observations, J. Geophys. Res., 95 (A5), 6375-6387, 1990.
Walker, I. K., Moen, J., Mitchell, C. N., Kersley, L., and Sandholt, P. E.: Ionospheric effects of magnetopause reconnection observed using ionospheric tomography, Geophys. Res. Lett., 25 (3), 293296, 1998.

Watanabe, M., Kablin, K. K., Sofko, G. J., Rankin, R., Gombosi, T. I., Ridley, A. J., and Clauer, C. R.: Internal reconnection for northward interplanetary magnetic field, J. Geophys. Res., 110, A06210, doi:10.1029/2004JA010832, 2005.

Øieroset, M., Sandholt, P. E., Denig, W. F., and Cowley, S. W. H.: Northward interplanetary magnetic field cusp aurora and highlatitude magnetopause reconnection, J. Geophys. Res., 102 (A6), $11349-11362,1997$. 